\title{
Reducing Cognitive Load in Multimedia-based College English Teaching
}

\author{
Jing Liu \\ School of Foreign Language, Qingdao University of Science and Technology, Qingdao, China \\ Email: rogerliu99@tom.com.
}

\begin{abstract}
Based on empirical research and qualitative analysis, this paper aims to explore reducing cognitive load in multimedia-based college English teaching. According to cognitive load theory of multimedia learning (CLTML), rational distribution of cognitive resources can effectively reduce cognitive overload. The findings of the study between the experimental group and the controlled group show that the average performance of the former in the test is much better than that of the latter, proving that instructional design guided by CLTML may facilitate reducing cognitive overload and enhance meaningful processing.
\end{abstract}

Index Terms—reducing cognitive load, multimedia, college English teaching

\section{INTRODUCTION}

Multimedia refers to the concurrent use of different material presentations through different sensory channels. Presentations can be either verbal (written text or audio) or pictorial (animation pictures. (Mayer, 2001) It cannot be denied that multimedia assisted approach can make English learning more interesting, and well-designed courseware can present the visual and auditory information the students needed easily and efficiently, saving a lot of time otherwise used in lecturing and blackboard writing. So multimedia has the potential to enhance people's cognitive capabilities (Mayer, 2001).

But the pre-study result that multimedia approach did not show its advantages over the traditional methods prompt us to reflect on the disadvantages of multimedia assisted approach in college English teaching. Long hours of watching courseware screen which is filled with text, sound, graphics, pictures, photographs, animation and moving video may constitute cognitive load and make the students become tired. What's more, in the face of so much information, some students will feel lost and not know what to choose. So the factors affecting the efficacy of computer-based multimedia must be assessed, and reduce cognitive load such as unnecessary pictures and animation, to maximize the probability of success when using multimedia.

\section{METHOD}

\section{A. Subjects}

The subjects for the study were selected, according to their English results of National College Entrance Examination and Pre-test, from first-year undergraduates of non-English majors in Qingdao University of Science and Technology where the researcher worked. Chinese was their L1, and English their L2 or foreign language. And there is no obvious difference among the two selected groups (Experimental group and Control group), we may take it for granted that the subjects roughly the same English proficiency.

\section{B. Instruments and Procedures}

In this study, the instrument used to elicit and collect information was in the form of test. The use of language tests as tools to measure the EFL learners' literacy has been well justified in the literature. In the current study, the subjects under different teaching courseware (experimental group, modified courseware, rationally distribute cognitive resources according to the Cognitive Load Theory of Multimedia Learning; while control group, courseware guided by Information Delivery Theory) took part in the same test. Their test results were collected and analyzed to see whether the multimedia teaching based on CLTML has positive effect on their English learning.

During the four-month experimental process, 117 subjects from two classes were taught English by the same teacher with the same textbook New Horizon College English. In the experimental group, the researcher, based on CLTML, presented the teaching materials according to the principle of dual channel presentation, spatial contiguity, temporal contiguity, coherence, modality, redundancy and so on, made full use of well-designed multimedia courseware which involves a rational combination of communication elements - text, sound, graphics, pictures, photographs, animation and video clips. Each media element has its own particular advantage in conveying particular kinds of messages and evoking particular kinds of learner responses. While in the control group, the courseware was designed according to IDT, paying attention to presenting large amounts of information with attractive graphics, pictures, photographs, animation, sounds, anecdotes, puzzles, giving more examples and practices to promote the students' cognitive schemata 
automation. The presentation of teaching materials was not limited by CLTML.

At the end of the experimental term, with a purpose of comprehensive test of the language proficiency of the subjects, both groups were asked to take part in the same test - the final examination which included writing, speed reading, listening comprehension, reading comprehension, cloze and translation. After the test, the test papers were carefully collected by the researcher.

\section{Data Analysis}

\section{Data Preparation}

In the quantitative study, a few steps were followed to prepare the data for statistical analysis. The raw data in the study was first inspected and as expected, some missing scores were found for the tests. However, to determine whether these scores should be treated as "missing" or "wrong", the researcher established the following procedures. First, if a subject made a reasonable attempt to answer the questions in the test, the questions left unanswered were treated as wrong and scored zero. However, if a subject left an entire test paper blank or if more than half of the questions were unanswered, the data were regarded as missing, and the subject was dropped from the statistics. In accordance with these conditions, the final number, which was of statistical value, of subjects in experimental group was 57, and the control group was 60 .

2. Scoring of the Tests

In the data analysis, all the object answers sheets were marked by the computer, and in order to get more convincible and persuasive results, the subject answers (writing and translation) were objectively marked by three different teachers rather than the researcher himself and the mean of the three scores were the final scores for the subject parts.

And the raw scores were carefully typed into the SPSS data table in order to gain the desired data.

\section{RESULTS AND DISCUSSION}

The results have been fed into SPSS (12.0) and analyzed using independent sample T-test analysis.

\begin{tabular}{|l|l|l|l|l|l|}
\hline & $\mathrm{N}$ & Mean & Std. Deviation & $\mathrm{t}$ & Sig.(2-tailed) \\
\hline Experimental Group & 57 & 75.52 & 9.79 & \multirow{2}{*}{2.251} & \multirow{2}{*}{.028} \\
\hline Control Group & 60 & 70.36 & 8.35 & 2.25 \\
\hline
\end{tabular}

The table shows that, in the test, experimental group and control group are different in the means; the former is 75.52 , and the latter 70.36, 5.16 lower than the experimental group. And the difference is significant $(\mathrm{P}=.028,<.05)$. This means that the two groups have different English proficiency. Therefore, the results of the test prove that, under different teaching courseware, the two groups do show difference, and the two different coursewares do affect the scores of the subjects. Or in another way, the cognitive load of the subjects can be controlled, guided by different theory; the teaching approach may affect the information cognitive processing of the subjects.

Limited by English proficiency, computer literacy, multimedia network learning environment adaptability, cognitive ability and learning style, self-efficacy, learning concept and emotional support, cognitive load may fluctuate, and English learning is a dynamic balance process of "input - output". Based on cognitive load theory of multimedia learning, the researcher of experimental group integrated the requirements of syllabus with the students' needs, facilitating students' cognitive processing of learning materials, expanding their working memory information processing capacity; and reducing their cognitive load. While based on the information delivery theory, in control group, the researcher's teaching highlighted information transmission, rich in content and informative, focusing on recreating the same materials to enhance students' memory, but limited working memory capacity making the students difficult to process them effectively. Invalid information flood can only lead to distraction effect.

\section{FURTHER DISCUSSION}

The objective of multimedia research for educational purposes is to determine the factors that enhance the information cognitive processing. The final goal is to improve learning outcomes (Mayer, 2001).

The CTML is based on three premises, (1) dual channels for processing visual and auditory information, (2) limited capacity to process information in each channel, (3) and the learners' active processing of information. Humans have two information processing systems that can be used simultaneously and complementarily but are qualitatively different (Paivio, 1986). Multimedia college English teaching enables the students to obtain auditory input while strengthening a lot of visual information, which might produce cognitive overload to the students, for too much visual input may be beyond the students' ability to have meaningful information processing . Generally speaking, the verbal channel might be appropriate for abstract information, while sensory experience, such as simulation or illustration of phenomena behavior can be presented visually. But when students need to focus their attention on abstract information the use of pictures or animation creates an external stimulus competing for cognitive resources (Mayer, 2001). In this case, pictures or animation distract students rather than help them (Mayer, 2001; Rieh, 2002). So the excessive use of pictures or animation, though may make the presentation seemingly attractive, more often than not, will have negative effect on the students' information processing. Pace of exposure, which refers to speed of material presentation, should also be 
paid attention to. Written information is self-paced, as opposed to audio and video, which are forced-paced. Pace of exposure is particularly important when considering the complexity of a message. People have less opportunity to process complex messages when pace of exposure is forced (Petty \& Cacioppo, 1986).

Layout design is another factor influencing multimedia effectiveness. According to Mayer (2001), based on extensive research, to develop effective multimedia presentations, pictures and their related words must be placed nearby and must be presented simultaneously. The extraneous materials should be avoided. And for animation it is better to use audio rather than written text. Due to the limited processing capabilities of the human brain, learners must select the relevant words and images to be processed. That is, the images and words processed on the working memory are already filtered. Therefore, the audio and pictures must be pleasant enough not to annoy, disturb or bore the learner. However, it can be speculated that the attractiveness should not be overdone because the most important feature is to present learners with relevant information to construct knowledge and not to distract them from the main objective.

Individual characteristics influence learning outcomes. Empirical findings suggest that domain-specific knowledge and spatial ability affects learning outcomes (Mayer, 2001). Learners with a low level previous knowledge about the presentation benefit more from a well-designed multimedia presentation than do learners with high level of previous knowledge (Mayer, 2001). In terms of spatial ability, learners with high spatial ability benefit more from a well-designed multimedia presentation as compared to learners with low spatial ability (Mayer, 2001). So the teachers might also need to cultivate the students' spatial skills so that they will be able to learn more from the multimedia presentations.

\section{CONCLUSION}

Foreign language learning is an unconscious transforming process. Compared to learning their mother tongue acquisition, English learners have to master more cognitive schemata and offer more efforts. Cognitive load theory of multimedia learning tells us that in real teaching situation we should pay attention to the contradiction between students' limited cognitive resources and excessive information processing. It is clear that multimedia can be an effective learning tool depending on how it is used. Multimedia per se does not ensure improved students' performance and satisfaction. The proper use of multimedia should be assessed to increase the probabilities of an effective use. For example, instructors must be aware that the match of information and channel is critical for multimedia success. And multimedia will be effective only if it is properly designed so as to reduce the learners' cognitive overload and improve the learning performance.

\section{REFERENCES}

[1] Andres, H. P. (2004). Multimedia, Information Complexity and Cognitive Processing. Information Resources Management Journal, 19 (1), 63-78.

[2] Cooper G. (1990). Cognitive Load Theory as an Aid for Instructional Design. Australian Journal of Educational Technology, (6) 108-113.

[3] Esperanza Huerta. (2006). Multimedia Influence on Learning. IRMA International Conference. (1) 472-474.

[4] Mayer, R. E. (2001). Multimedia Learning. Cambridge, UK: Cambridge University Press.

[5] Paivio, A. (1986). Mental Representations: A Dual Coding Approach. Oxford, England: Oxford University Press.

[6] Petty, R. E., \& Cacioppo, J. T. (1986). The Elaboration Likelihood Model of Persuasion. In L. Berkowitz (Ed), Advances Experimental Social Psychology (Vol. 19, pp. 123-203). San Diego, CA: Academic Press, Inc.

[7] Rieh, S. Y. (2002). Judgment of Information Quality and Cognitive Authority in the Web. Journal of the American Society for Information Science and Technology, 53(2), 145-161.

Jing Liu was born in Qingdao, China in 1974. He received his M.A. degree in linguistics from Ocean University of China, in 2006.

$\mathrm{He}$ is currently an associate professor in the School of Foreign Languages, Qingdao University of Science and Technology, Qingdao, China. His research interests include applied linguistics and pragmatics. 